\title{
HISTOPATHOLOGICAL CHANGES ASSOCIATED WITH VARIOUS TYPES OF PARASITIC INFECTIONS, CAUSING MORTALITY OF MIGRATORY GREATER FLAMINGO, PHOENICOPTERUS RUBER ROSEUS.
}

\author{
OMAR A.S. TAMAM
}

Department of Natural Resources, Environmental Studies and Research Institute, University of Sadat City, Sadat City, Egypt E-mail: otamam2002@ hotmail.com

\section{ABSTRACT}

Received at: 8/12/2014

Accepted: 25/12/2014
Flamingo mortalities recorded in Egypt were investigated using parasitological, light, and transmission electron microscopy. During the period 2009-2014, a total of 27 flamingos were examined. Traumatic Myopathy recorded in the major cases 20 cases of 27 which appeared as pectrol, superficial and deep leg muscles heamatoma, pulmonary congestion and oedema, swollen kidneys, with a dark cortex. In addition to hepatocellular necrosis and dilatation of liver sinusoids, loss of the glomerular tuft cellularity and necrosis of the proximal convoluted tubules. Sarcosyts $(n=2)$ were observe in the esophagus and intestinal wall of two birds. Blood films stained with Giemsa stain showed the presence of trypanosome sp (one case) between the blood cells. Ehrichlia organism $(n=20)$ in the cytoplasm of monocytes. Ehrichlia organisms were identified as vacuole micro-colonies (morula) in the spleen and the intestinal muscularis mucosal layer by Transmission electron microscopy. Flamnigolepis liguloides, cestodes (Hymenlopididae) was detected and identified. These cestodes resulted in massive necrosis of intestinal mucosa. Intestinal coccidiosis $(n=7)$ showed severe tissue damage, necrosis and disintegration of glandular epithelial cells, hemorrhage in the sub-mucosa and plenty of schizonts and oocysts. Tetrameriasis were observed in the proventriculs of all birds $(n=27)$ and resulted in atrophy of the proventriculus. Flamingo wing louse was identified as Anaticola phoenicopteri and recorded in all cases $(n=27)$. Amyloidosis recorded in all cases which appeared as Focal amyloidosis of the spleen and associated with spontaneous splenic rupture and suggested altered immune function occurred. It was concluded that the mortality of the migratory flamingo related to multifactorial agents started from the presence of stress, blood parasites, intestinal parasites resulted in several alterations in tissues to be the main causes of mortalities. Moreover, it is recommended to improve their European habitat before migration in order to minimize mortalities.

Keywords: Flamingo-Sarcosyts-Tetrameriasis- Ehrichlia- coccidiosis- Trypanosome

\section{INTRODUCTION}

Flamingo (phoenicopterus spp.) are very long - lived birds (fowler and Cubas 2001) and present a variety of health problems in captivity (Hagen $\mathrm{K}$. et al., 2014). Trauma is mentioned as one of the most common medical issues in zoos (F. Wyss. et al., 2014). Endoparasites and ectoparasites are also common findings. According to Zschieshe and jakob (1989), phoenicopteriformes show a particularly high incidence of amyloidosis. Lice belonging to the same genera as those found on waterfowl are seen in captive and free-living birds (Lamberski, 1998). Tetrameres americana and $T$. coccinea are commonly found in ductal areas of the proventricular glands with no associated inflammation in wild Phoenicopterus ruber ruber (Aguirre et al., 1991).
Tetrameres spp. have been problematic in some captive flamingos at The Wildfowl and Wetlands Trust in Slimbridge (Humphries et al., 1976). Cestodes in the genus Amabilia, Cladogynia, Sobolevicanthus, and Gynandrotaenia, have been found incidentally in free-ranging flamingos (Aguirre et al., 1991), however, cestodes were found to cause an intestinal diverticulosis in a captive lesser flamingo (Poynton et al., 2000). The objectives of the present study are to investigate possible etiologies and describe the histopathological changes associated with Greater Flamingo mortalities.

\section{MATERIALS and METHODS}

A total of 27 captured migratory greater flamingos, were examined from September 2009 to November 
2014. Birds were subjected to a routine post mortem examination (Harrison \& Harrison 1986). Samples for histopathological and parasitological examination were taken to confirm initial diagnosis. Prick the brachial vein, located crossing the "elbow" joint of the alive bird's wing $(n=27)$ with a small needle. The blood is collected with a microcapillary tube. Two thin blood smears were obtained for each bird and stained with Leishman and Giemsa's stain and examined for blood parasites at $1000 \mathrm{x}$, and were identified using morphologic characteristics (Garnham, 1966). Cestode were prepared by flattening the worms between two slides and keep in refrigerator for 2 hours then transfer to $2 \%$ formalin for one hour, then $5 \%$ aceto-formal $(5 \%)$ formalin plus $2 \%$ glacial acetic acid (for one hour, washed in water for one-half hour, stained overnight in Delafteld's hematoxylin plus .01 per cent aceto carmine, washed in water, dehydrated in 15 per cent, 30 per cent and 60 per cent alcohol, destained in 10 per cent acid alcohol ( 3 per cent hydrochloric acid) until a pale pink color obtained. They were then changed to 80 per cent alkaline alcohol and let remain until a pale blue color was obtained. The worms were next placed between two micro slides and bound with a rubber band, dehydrated in $80 \%, 90 \%, 95 \%$ and absolute alcohol for one hour in each grade. Cleaned in xylo-alcohol for one-half hour'pure xylol for one hour and mounted in balsam.

\section{Transmetion electron microscopy (TEM)}

Tissue blocks (1-4mm in diameter) were fixed in modified Karnovsky solution, post-fixed in $2 \%$ osmium tetroxide solution, immersed in $2 \%$ tannic acid solution for 1 hour at room temperature, and dehydrated in an increasing series of ethanol and propylene oxide and embedded in Spurr resin. Thin sections were prepared using an ultra microtome (Ultra-Cut; Reichert) with a diamond blade, mounted on 200 and 300 mesh grids, counterstained with uranyl acetate andlead citrate, and examined using the Joel JSM1010at transmission electron microscope at $100 \mathrm{kV}$.

\section{RESULTS}

Many Flamingos live in captivity at zoos and wildlife parks around the world. They seem to adapt very well to such a lifestyle even breed in captivity (Fig.1). Unsuitable habitat considered as mechanical stresses let the recently captured migratory birds suppressed, unaclamatized with the surrounding and become Fear, anxiety then recumbent and survive for a few days. (Fig.2). Gross lesions of all of the examined cases showing small to wide areas of edema, and hematoma in the leg's muscles and pectrol muscles (Figs. 3a,b), lungs showed multiple discrete, round, red-brown foci of consolidation expressed histopathologically by monocellular inflammatory cellular infiltration and hyperemia (Fig. 4 a,b). Focal paleness of the liver (Fig. 4,c). Expressed by focal area of lymphocytic infiltration, dissociation of hepatic cords, and hepatocellular necrosis (Fig.4 d). The liver sinusoids were also dilated and filled with nucleated red blood cells (Fig.4 d).

In addition (Fig. 5,a) showed loss of cellularity of the glomerular tuft and obliteration of the Bowman's capscule. Moreover, necrosis of the epithelium lining the proximal convoluted tubules was also observed (Fig. 5,b). The spleen of flamingo showed focal area of amyloidosis and expressed by the deposition of homogeneous acidophilic material in the splenic follicles (Fig. 5,c). Moreover, necrtotic changes of the splenocytes of the white pulb were exhibited with karyorehxis of the nuclei (Fig. 5,d). Electronmicroscopy conform true diagnosis of amyldosis substance which appeared as fibrils inbetween the splenocytes (Fig. 5,e).

Blood films stained by Giemsa stain revealed the presence of basophilic organisms in the cytoplasm of monocytes and identified as Ehrilchia spp. (Fig.6). Examination of the flamingo's spleen by EM revealed masses of Ehrilchia spp which appeared as vacuole micro colonies in the red pulb (Fig.7 a,b) and intercellular space of the intestinal muscular layer (Fig. 7 c,d). Moreover, Trypansoma spp. was recorded in blood films (Fig.8). Flamnigolepis liguloides, cestodes as described (Hymenlopididae, Gervaiss, 1847) was also identified (Fig.9a,b). Histopathological examination revealed the presence of these adult cestodes in the intestinal lumen resulted in massive destruction of the intestinal epithelia lining the mucosa (Fig.9,c). Moreover, invasion of these cestodes was also observed into the superficial mucosa in close association with the crypts of Liburkhan (Fig.9,d,e,f). Sarcocysts was identified in the oesophagus of flamingo and appeared as fusiform to oval with a mean cyst size 2 X0.2 mm (Fig.10 a). Also detected in the intestinal wall mainly in the muscularis and in close association with the crypts. Such invasion resulted in pressure atrophy and necrosis of the intestinal mucosa with little eosinophilic infiltration (Fig.10,b). Intestinal coccidiosis recorded in 7 cases, histopathologicaly the endogenous stages of the parasites were found in the small intestine. These were usually located in the villi, mainly above the nucleus of apical epithelial cells, or in the medium portion close to the glands, the macrogametes with its peripheral granules invade the crypts of liberkhun with Intense lymphocytic and eosinophilic cellular reaction (Fig. $10 \mathrm{c}, \mathrm{d}$ ), inflammatory cells influxes into the sub mucosa and thickened mucosa and sub mucosal layer with slightly congestion of blood vessel necrotized and denuded epithelial mucosa. 
Teterameres Spp. were also observed in the proventriculus of all of the examined flamingo resulted in atrophy of its glandular tissues with detachment and swelling of the surrounding fibrous capsule (Figs. 11) compared to the non-infested normal proventriculus showing folds of mucous membrane (P); deep proventricular glands (GP); capsule (connective tissue) around the glands (arrow head); muscle layer $(\mathrm{m})$; serosa (connective tissue) with blood vessels (S), and the lumen (L) (Fig.12). Louse were detected from the wings of flamingo and identified as Anaticola phoenicopteri (Fig.13).

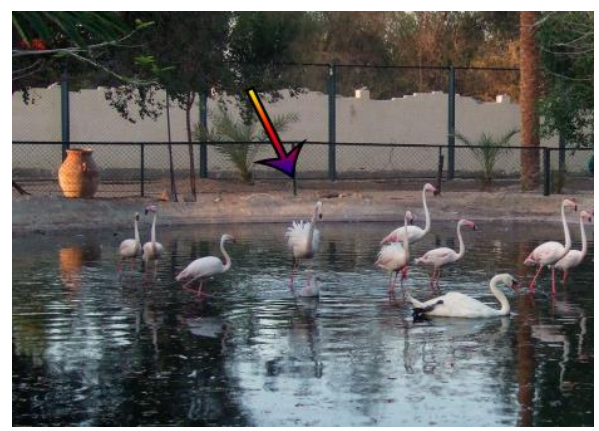

Fig. 1: Breeding of the greater Flamingo birds in

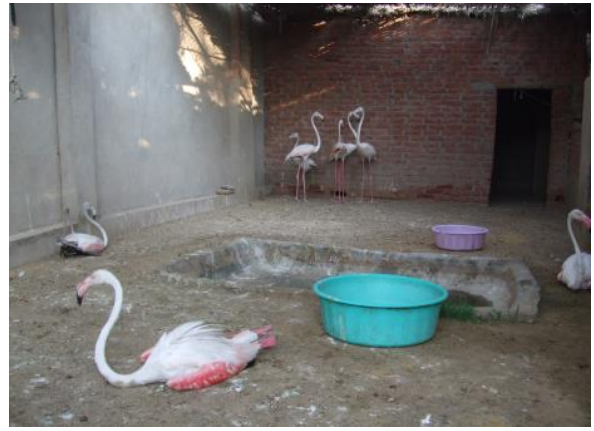

Fig. 2: Recumbence and death are the end results of this habitat.

the suitable habitat.

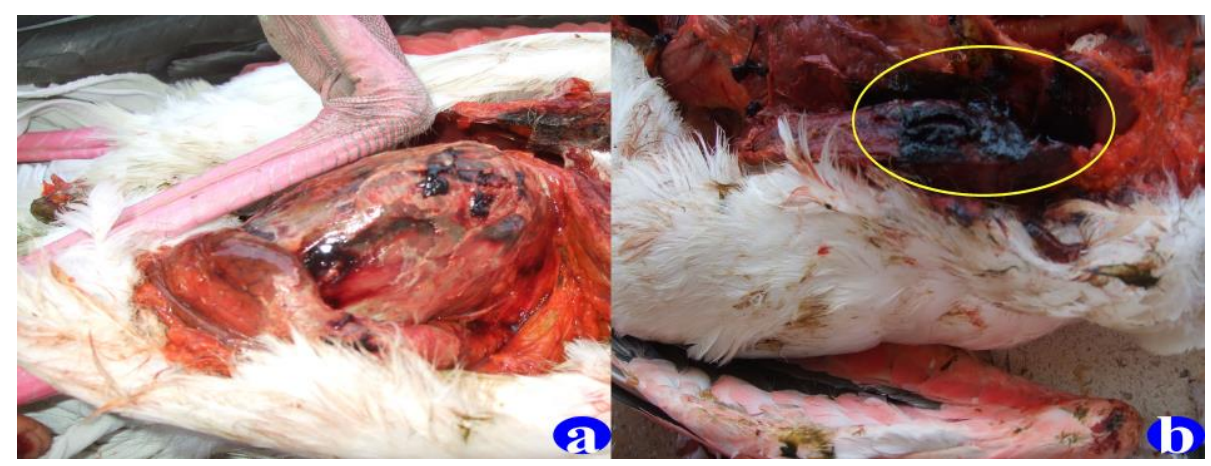

Fig.3: Subcutaneous edema (a) and Massive wide bleeding in the leg and pectoral muscles hematoma (b).

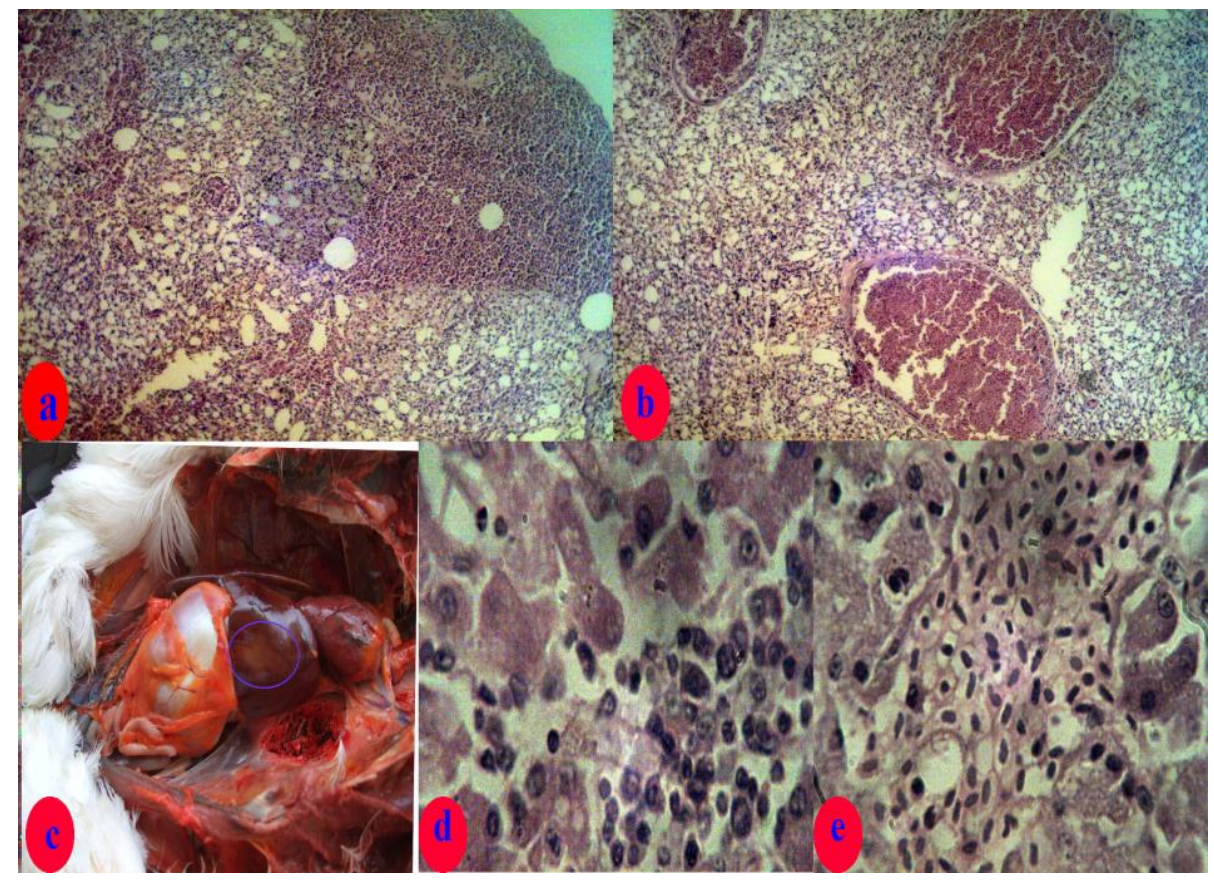

Fig.4: Lungs showing area of consolidation expressed by monocellular inflammatory cellular reaction and hyperemia. H.\&E. 10x.(a), with vascular changes expressed by hyperemia of blood vessels (b). H.\&E. 40x. the circle surrounded focal area of paleness on the liver (c), focal inflammatory cellular reaction made of lymphocytes, dissociation of hepatic cords and hepatocytes necrosis. H.\&E. 400x. (d). The liver sinusoids are dilated and filled with nucleated RBCs as well as necrotic hepatocytes H.\&E. 400x (e). 


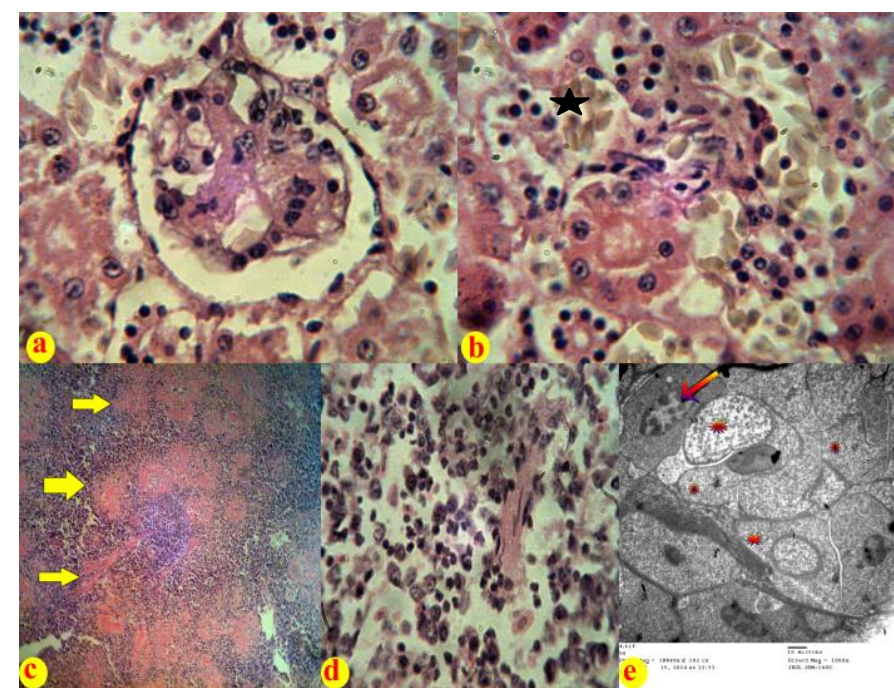

Fig.5

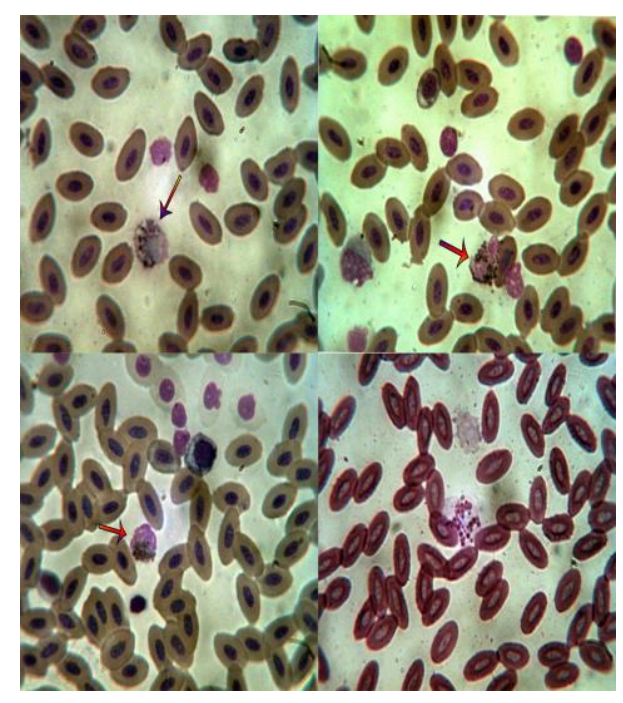

Fig.6

Fig. 5: Kidney showing progressive loss of cellularity of tufts with glomerular atrophy and Shrinkage. H.\&E. 400x(a). Necrosis of the epithelial lining the proximal convoluted tubules (star). H.\&E. 400x.(b).

Focal deposition of homogenious acidophilic amyloid material in the white pulb of flamingo spleen (arrow).

H.\&E.10x.(c). Necrotic changes of the lymphocytes of the white pulb expressed by Karyorehexis of the nuclei. H.\&E. 400x

(d). TEM showing karyorhexix of splenocytes nuclei (arrow) and deposition of fibrils-like amorphous

amyloid material between splenocytes (stars). 1000x.(e).

Fig. 6: Blood smear of Flamngo stained by Giemsa stain showing Ehrichila in the cytoplasm of monocytes (arrow). 400x.
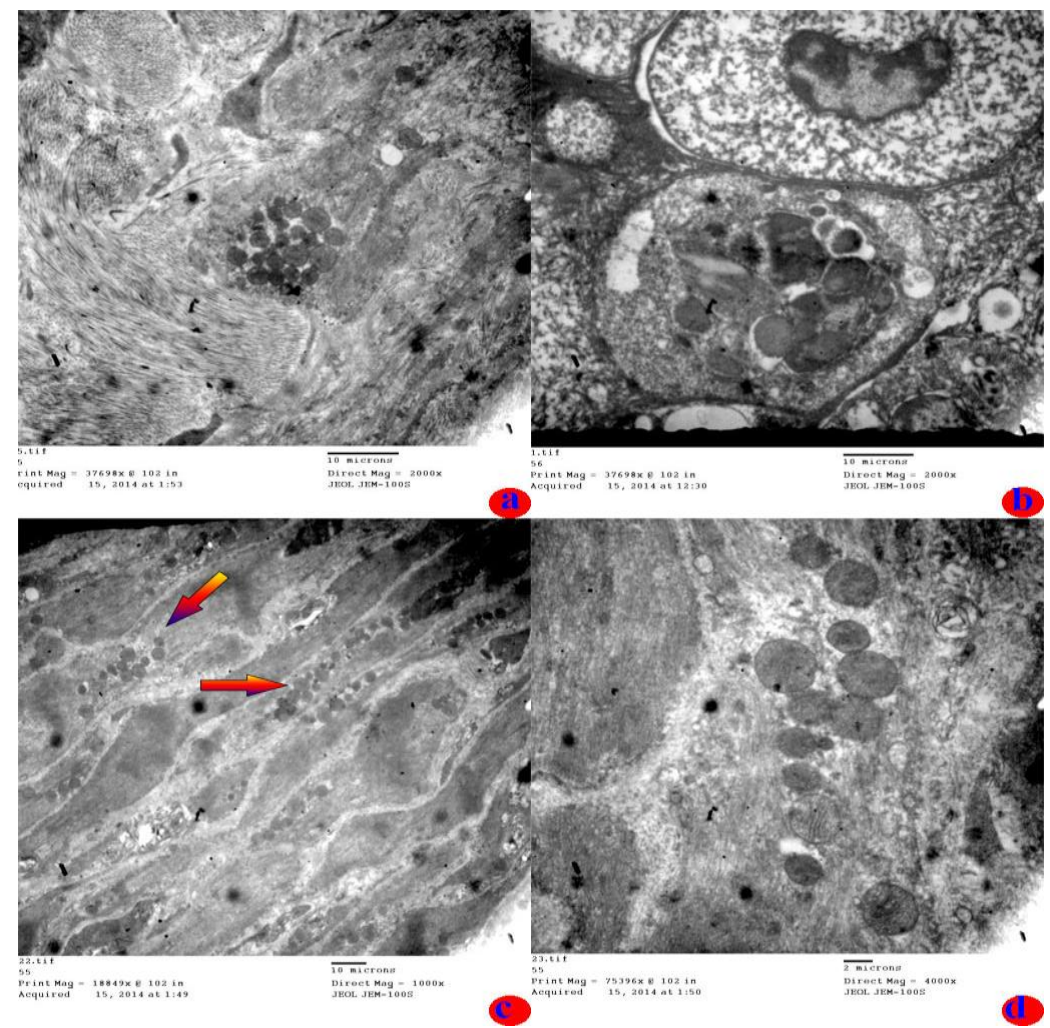

Fig. 7: TEM showing accumulation of morula of Ehrilichia between the trabeculae of spleen. 2000x(a,b) and in between the intestinal muscular fibers as vacuole micro-colonies (arrow) of Erchlihia (morula). X4000(D). 

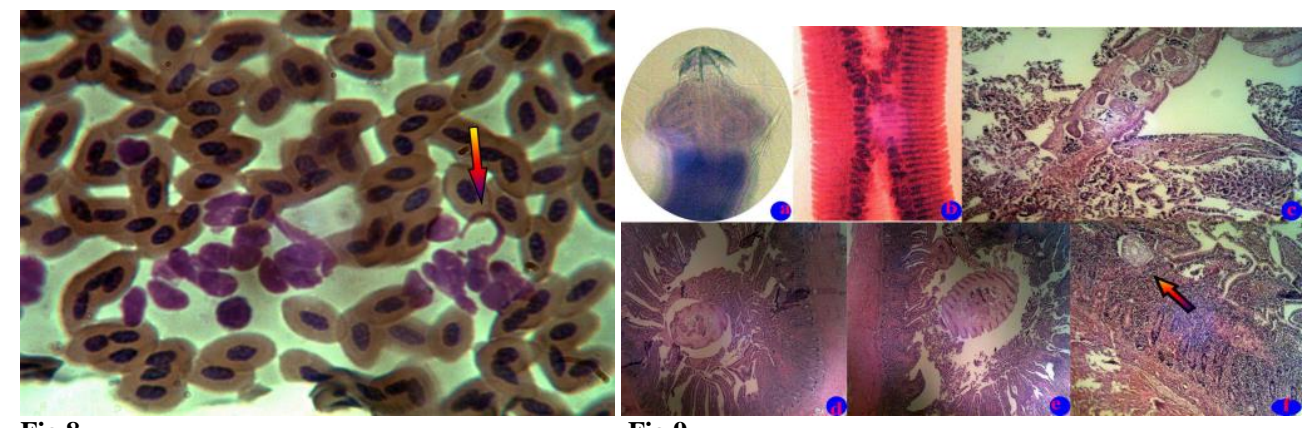

Fig.8

Fig.9

Fig.8: Blood film stained with Giemsa showing trypansoma sp.between the nucleated red blood cells of Flamingo. Giemsa stain 1000x.

Fig.9: Flamnigolepis liguloides, cestodes (Hymenlopididae, Gervaiss,1847) $(\mathrm{a}, \mathrm{b})$. Adult cestodes in the intestinal lumen and attached to the mucosa. Note the necrotic intestinal mucosa (arrow). H.\&E. 100x (c).Cross section of the cestsodes invading the superficial area of intestinal submucosa (arrow). H.\&E. 10x(d,e,f).

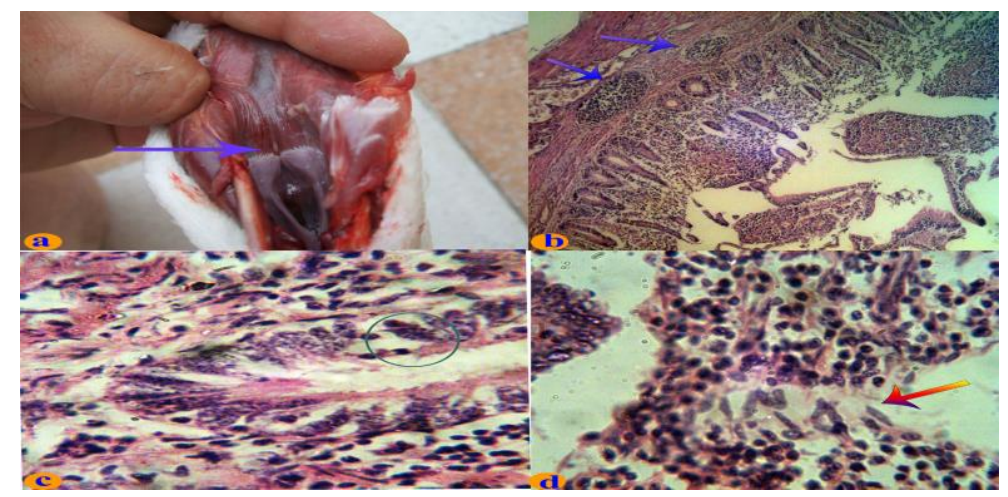

Fig. 10: Sarcocysts invading the esophagus of Flamingo (Big arrow) (a) and invading the muscular layer of intestine. Necrosis of the intestinal mucosa with eosinophilic infilteration. H.\&E.100x(b). Crypts of Liberkhun of the intestine invaded with macrogametes of coccidia (circle) with peripheral granuleds. H.\&E. 1000x. Higher magnification of (c) showing abundant spindle shaped macrogametes of coccidia (arrows) surrounded by lymphocytic and few eosinophilic cells (star). H.\&E. 1000x.

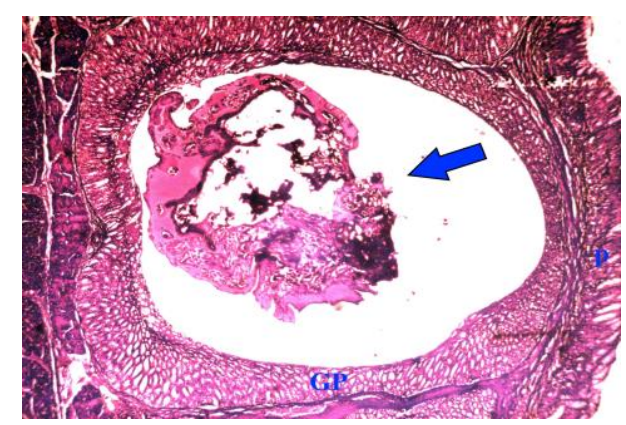

Fig.11

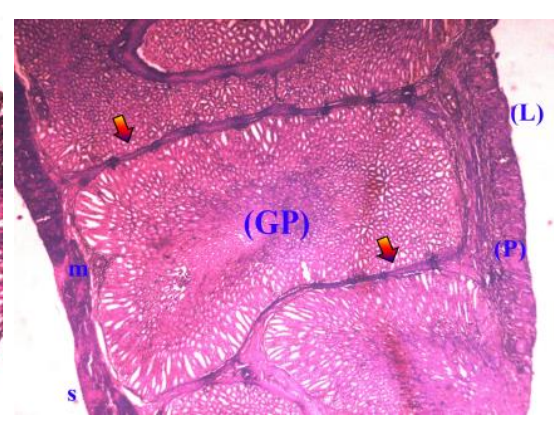

Fig.12

Fig.11: Cross section of Tetrameres spp. in proventriculitis (arrow). The proventriculus glands were atrophied. H.\&E. 40x

Fig.12: Normal proventriculus showing folds of mucus membranes (P), proventriculus glands (GP), thick proventriculus glandular capsule (Head arrow), muscular layer (m), serosa(s), and lumen (L). H.\&E. 40x.

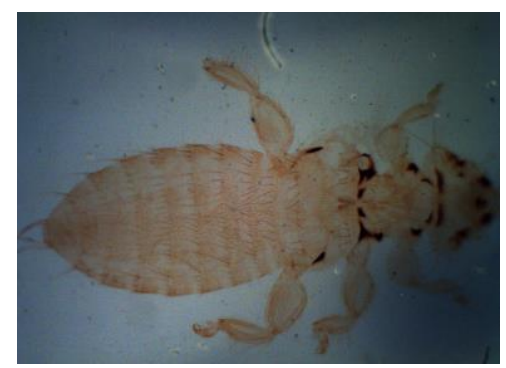

Fig. 13: Flamingo wing louse, Anaticola phoenicopteri (Coinde, 1958). 


\section{DISCUSSION}

It is apparent from this study that flamingo could harbor different parasites which might be responsible for mortalities either during migration and/or poor management in captivity.

Kamil et al. (2011) stated that Tetrameres spp., (Nematoda: Spiruridae) are parasites of poultry and wild birds prevalent throughout the world. Members of this genus exhibit strong sexual dimorphism. Mature females are almost spherical, dark blood-red in color, and have four longitudinal furrows which correspond to the medium and lateral lines. Tetrameres are found buried in the mucus glands of the proventriculus. Histopathological examination of proventriculus revealed dilation of the gland lumen, atrophy, degeneration and desquamation of the glandular cells. Sections of the parasite containing embryonated eggs were observed in the glandular lumen (Kamil et al., 2011). In the present study similar histopathological changes were observed in the proventriculus of flamingo.

Cestodes were identified in the present study and described as Flamnigolepis liguloides, cestodes (Hymenlopididae, Gervaiss, 1847). These parasite was attached in the intestinal mucosa resulted in massive destruction of the mucosa. It was also observed invading the superficial layers of the subnucosa in close association with the Liberkhun crypts. Anderson et al. (1978) stated that the number of eosinophils increased significantly in the infected mice. A significant increase in mast cells and globule leucocyte formation was observed in the infected mice. No changes in the villus/crypt ration in the jejunum were observed.

In the present study, Flamingo wing louse, Anaticola phoenicopteri (Coinde,) was detected and identified. A recent analysis of three genes from avian feather lice (Ischnocera) indicated that the grebe louse genus Aquanirmus is the sister taxon of Anaticola, one of the genera that parasitizes both flamingos and ducks (Smith et al., 2004). Moreover, similarity of the louse faunas of flamingos and ducks is a result of host switching from flamingos to ducks, rather than from ducks to flamingos (Smith et al., 2004).

In the present study, macrogamete of coocidiosis appeared as spindle shaped with peripheral granules attached to the crypts of Liberkhun. Also, were surrounded by eosinophils and lymphocytes.

Genus Ehrlichia contains obligate intracellular gram positive bacteria belonging to the family Rickettsiaceae, characterized by their unique tropism for circulating leucocytes and platelets. Several Ehrlichia spp. can be transmitted to a variety of hosts in nature, including dogs, horses, cats, roe-deers, boars, bears, mooses, chamois, birds and human beings (Tarello, 2006c). Genus Ehrlichia contains obligate intracellular gram positive bacteria belonging to the family Rickettsiaceae, characterized by their unique tropism for circulating leucocytes and platelets. Definitive diagnosis is made by cytological demonstration of morulae (i.e., inclusions formed by clusters of rickettsiae) in leukocytes or by PCR. Wild birds carrying infected ticks may be reservoir hosts for Ehrlichia chaffeensis, the agent of human monocytic ehrlichiosis (HME) and for Anaplasma phagocytophilum, the zoonotic agent of granulocytic ehrlichiosis (Tarello, 2006c). Normal falcon monocytes do not possess granules (Wernery et al., 2004). Occasionally, cells with cytoplasmatic granules have been seen in the peripheral blood of falcons and have been defined as 'toxic granulations' associated with underlying systemic illness (Wernery et al., 2004). This definition is compatible with the diagnosis of ehrlichiosis.

In the present study, cytoplasmic granules were observed in the leukocytes in blood films stained by Giemsa. Moreover, the morula stage appeared as vacuole microcolonies (morula) in the red pulb by transmission electron microscopy Focal amyloidosis was observed in the present study as eosinophilic deposition in the white follicle of the spleen and could suggest altered immune function could occur. Moreover, necrotic changes were observed in the splenocytes expressed by karyorehexix. These changes were also observed by electron microscope. Tosoni et al. (2011) described Structural definition of amyloid differs from those used for diagnostic purpose .Pathologists define amyloid on the basis of its presentation in pathological tissues, namely: extracellular deposition of protein with characteristic fibrils appearance in electron microscopy -EM-, typical X-ray diffraction pattern and affinity for Congo red with concomitant green birefringence. In advanced amyloidosis, older amyloid deposits can appear as dense ovoid-globular aggregates, or in homogeneous deposits with multi-focal accumulation of densely packed short fibrils and filaments.

In conclusion, the presence of parasites associated with several alterations in different organs and tissues in the present study which could been the main cause (s) of mortalities observed in flamingo. Moreover, it is recommended to improve the hygienic habitat in order to minimize mortalities.

\section{REFERENCESS}

Aguirre, A.A.; Cook, R.S.; McLean, R.G.; Quan, T.J. and Spraker, T.R. (1991): Occurrence of potential pathogens in wild Caribbean flamingos (Phoenicopterus ruber ruber) during a lead poisoning die-off in Yucatan, Mexico. J. Zoo Wildlife Med. 22: 470-475. 
Andreassen, A.; Hindsbo, O. and Ruitenberg, E.J. (1978): Hymenolepis diminuta infections in congenitally athymic (nude) mice: worm kinetics and intestinal histopathology. mmunology. 34(1): 105-113.

Chubb, AL. (2004): New nuclear evidence for the oldest divergence among neognath birds: the phylogenetic utility of ZENK (i). Molecular Phylogenetics and Evolution, 30(1), 140-151.

Wyss, F.; Wolf, P.; Wenker, C.; Hoby, S.; Schumacher, V.; Béchet, A.; Robert, N. and Liesegang, A. (2014): Comparison of plasma vitamin $\mathrm{A}$ and $\mathrm{E}$, copper and zinc levels in free-ranging and captive greater flamingos (Phoenicopterus roseus) and their relation to pododermatitis. Journal of Animal Physiology and Animal Nutrition 98:10.1111/jpn. 2014. 98. issue-6, 1102-1109.

Fowler, M.E. (2001): Phoenicopteriformes. In Fowler, M.E. and Cubas, Z.S. (eds). Biology, Medicine and Surgery of South American Wild Animals. Iowa State Press.

Garnham, PC. (1966): Malaria Parasites and Other Haemosporidia, Blackwell Scientific Publications, Oxford.

Hagen, K.; Espie, I.; Lane, E.P.; Kotze, A.; Wyss, F.; Clauss, M. and Codron, D. (2014): Mortality and diseases in greater flamingo (Phoenicopterus roseus) and Carribean flamingo (Phoenicopterus ruber) kept at the National Zoological Garderns of South Africa. Proceedings of the International Conference on Diseases of Zoo and Wild Animals, p 57-64.

Harrison, G.J. and Harrison, L.R. (1986): Clinical Avian Medicine and Surgery. W.B. Saunders Company, Philadelphia.

Hoagstrom, C.W. (2002): Respiration in Birds. Magill's Encyclopedia of Science: Animal Life. Pasadena, California, Salem Press. Vol 3, pp 1407-1411.

Kamil, S.A.; Darzi, M.M.; Mir, M.S.; Shah, S.A.; Shah, S.N. and Khan, F.A. (2011): Tetrameres
Fissispina Infection in Ducks from Bandipora Area of Kashmir Valley Israel Journal of Veterinary Medicine, Vol. 66 (2), 43-47.

Lamberski, N. (1998): The medical management of flamingos. Proceedings of the North American Veterinary Conference, Orlando, FL. pp 880-882.

Mayr, G. (2004): "Morphological evidence for sister group relationship between flamingos (Aves: Phoenicopteridae) and grebes (Podicipedidae)" (PDF). Zoological Journal of the Linnean Society 140 (2): 157-169.

Poynton, S.L.; Mukherjee, G. and Strandberg, J.D. (2000): Cestodiasis with intestinal diverticulosis in a lesser flamingo (Phoeniconaias minor). J Zoo Wildlife Med 31: 96-99.

Smith, V.S.; Page, R.D.M. and Johnson, K.P. (2004): Data incongruence and the problem of avian louse phylogeny. Zool. Scr.; 33: 239-259.

Tosoni, A.; Barbiano di Belgiojoso, G. and Nebuloni, M. (2011): Electron Microscopy in the Diagnosis of Amyloidosis, Amyloidosis Mechanisms and Prospects for Therapy, Dr. Svetlana Sarantseva (Ed.), ISBN: 978-953307-253-1,

from:http://www.intechopen.com/books/amylo idosis-mechanisms-and prospects-fortherapy/electron-microscopy-in-the-diagnosisof-amyloidosis.

ARELLO, W. (2006c): Microscopic and clinical evidence for Ehrlichia spp. infection in Saker falcons (Falco cherrug). Revue de Medecine Veterinaire, 157, 203-204.

Wernery, R.; Wernery, U.; Kinne, J. and Samour, J. (2004): Colour Atlas of Falcon Medicine. Schlutersche Verlagsgesellschaft $\mathrm{mBH} \&$ Co., Hannover, 2004, 93-96.

Zschiesche, W. and Jakob, W. (1989): Pathology of animal amyloidosis. Pharmacology and Therapeutics, 41, 49-83.

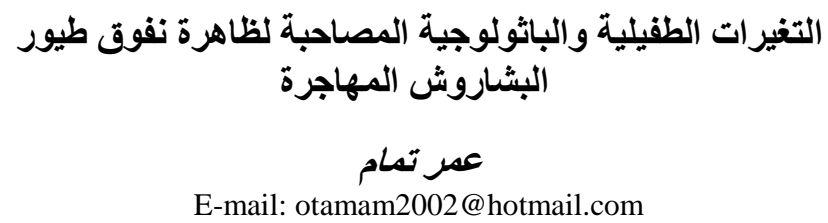

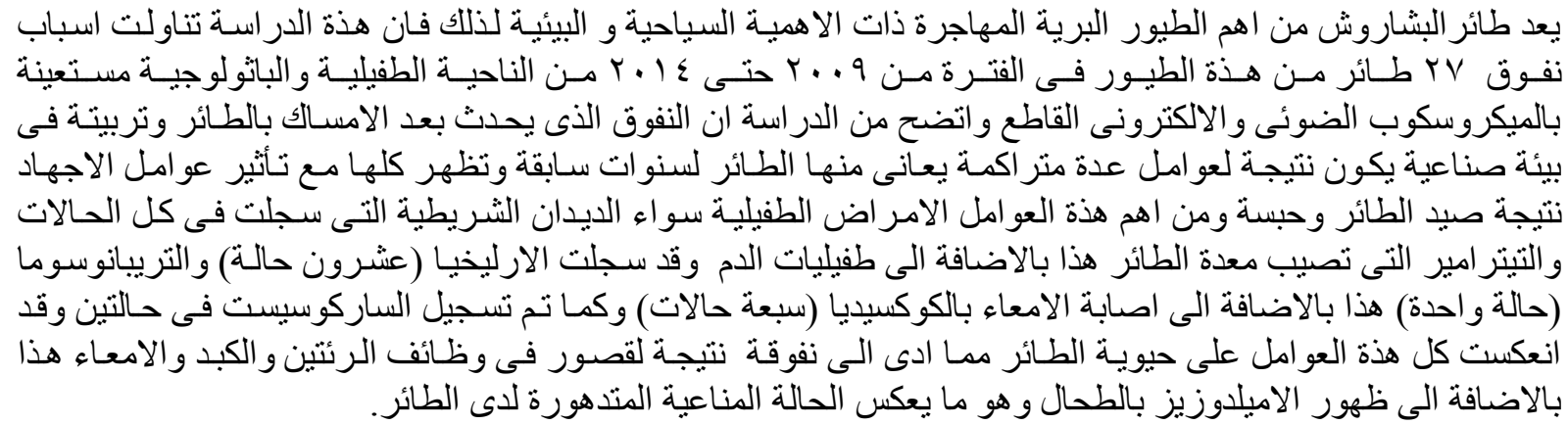

